\title{
DUCTILE IRON OPTIMIZATION APPROACH FOR MECHANICALLY AND THERMALLY LOADED COMPONENTS
}

\author{
Jarkko Laine ${ }^{(1)}$, A. Leppänen, and J. Vaara \\ Wartsila Oyj, Järvikatu 2-4, 6500 Vaasa, Finland \\ K. Jalava and J. Orkas \\ Department of Mechanical Engineering, Aalto University, Espoo, Finland \\ T. Frondelius \\ Materials and Mechanical Engineering, University of Oulu, Oulu, Finland
}

Copyright (c) 2020 The Author(s)

https://doi.org/10.1007/s40962-020-00529-9

\begin{abstract}
The mechanical and thermal properties of ferritic-pearlitic ductile irons vary widely according to their silicon and pearlite contents. Thus, different combinations of silicon and pearlite affect components' lifetime under mechanical and thermal stress. An excellent example of the usage of

estimation of the optimal ductile iron composition are presented in this study. The approach allows selection of the most suitable base composition for subsequent analyses, such as casting simulation and final accurate finite element modelling and fatigue calculations.
\end{abstract} such irons is combustion engine cylinder heads. They experience transient thermal loading (heating and cooling) during starting and stopping in addition to mechanical loading (combustion) during engine operation. An optimization approach and calculation models for the
Keywords: ductile iron, thermal conductivity, elevated temperature properties, optimisation

\section{Introduction}

Factors such as reliability and durability are the primary targets for the structural analysis of components. Current design processes take account of integral boundary conditions, such as component geometry, and optimize them in order to achieve the set objectives. ${ }^{1-3}$

Large combustion engines contain many components that operate under combined thermal and mechanical loads. Cylinder heads are one of the most loaded of these, experiencing static, thermal and dynamic loads during operation. Maximum combustion pressures of modern large engines are well over 200 bar (20 MPa). Static loads arise from pre-tensioning forces. Such pre-tension is used, for example, to ensure cylinder head sealing tightness during combustion. ${ }^{4}$
Depending on engine size, the combustion load of such engines (high-cycle load) is between 250 and 600 cycles per minute ( 0.5 times the revolution speed). At engine start, the cylinder head heats to its operating temperature and cools to the ambient temperature when the engine stops. This causes substantial thermal gradients and stresses and is known as low-cycle loading. Variable temperature fields not only determine critical locations but are also decisive in reducing the number of cycles before failure, both in the high- and low-cycle fatigue regimes. Fast ramp-ups and ramp-downs result in high thermal gradients and stresses, generally making low-cycle fatigue the limiting factor in final component life.

Under these kinds of loads, material selection is a critical part of the structural design. An optimal selection process considers both thermal and mechanical properties carefully. This study aims to develop a methodology that can be used for selection of an optimized ductile iron 

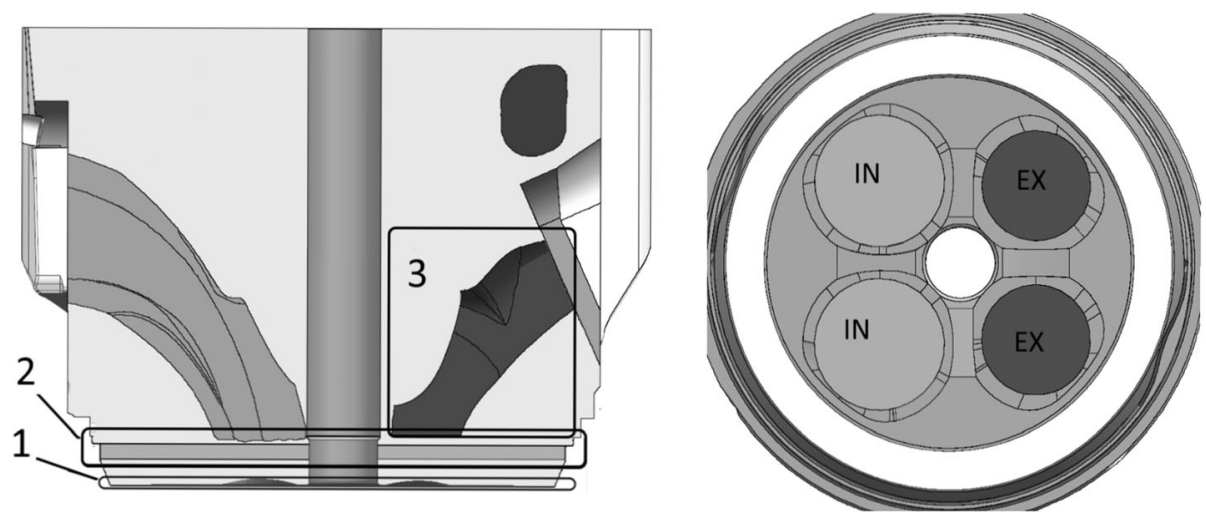

Figure 1. Schematic picture of the cylinder head, studied areas (1) flame plate, (2) coolant channel area, (3) exhaust channel.

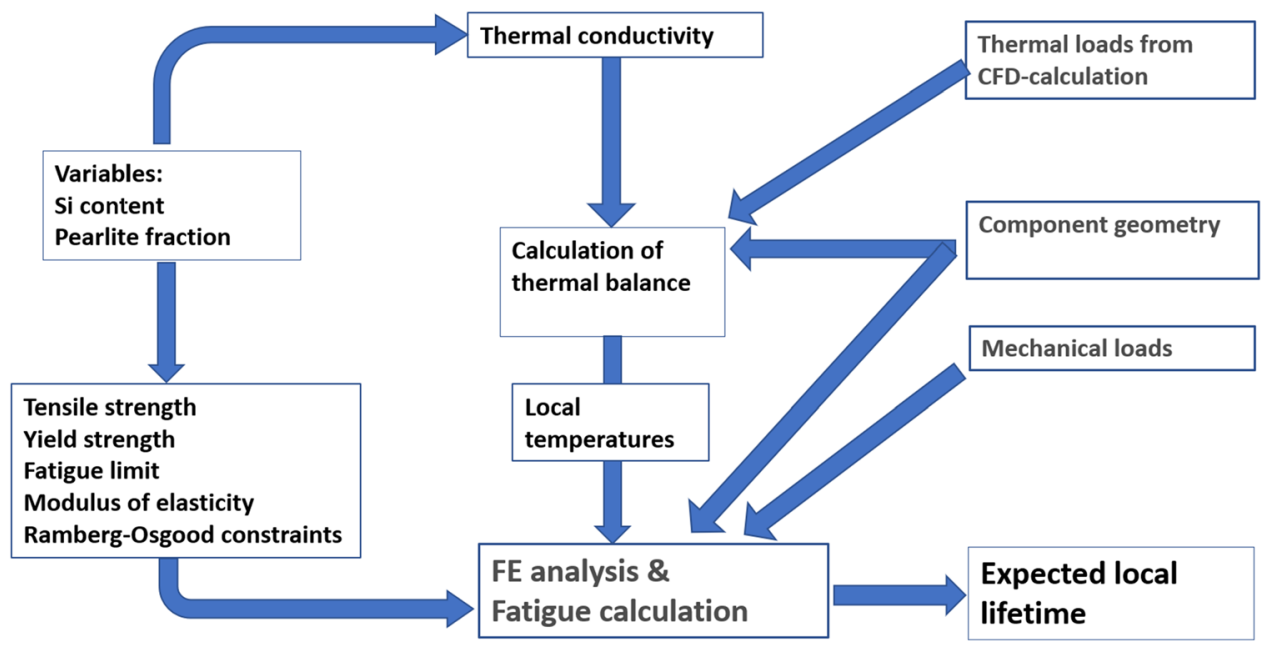

Figure 2. Optimization loop.

composition for a thermally and mechanically loaded component. The method is finally applied to the analysis of a cylinder head, illustrated in Figure 1.

\section{Approach}

The approach presented in this study relies on numerical analysis, where material properties depend on silicon content and the pearlite fraction. The thermal conductivity ${ }^{5}$ and mechanical properties ${ }^{6}$ of ductile iron can be described to a large degree as a function of silicon content and the pearlite fraction, as the spheroidal form of graphite contributes relatively little to these material property variables compared to other forms of graphite. These variables are used in the optimization loop shown in Figure 2.

The three most critical areas of a cylinder head were selected for analysis and are shown in Figure 1: the flame plate, coolant channel area and exhaust port walls.

\section{Materials and Material Modelling}

Cast irons can be generally described as composite materials with an iron-based matrix and variable forms of graphite particles. The shape of the graphite inclusions is the base definition of cast iron types. These shapes include lamellar (also known as grey), vermicular (compacted) and spheroidal (ductile) forms.

Due to their relatively good mechanical properties, ductile irons are frequently used in various mechanical engineering applications. The castability of ductile irons is excellent, especially compared to various cast steels. For example, ductile iron possesses a lower melting and pouring temperature, better flowability and lower shrinkage values. ${ }^{7}$

Without special alloying or treatments, the matrix microstructure of ductile iron is ferritic, pearlitic or a combination of both phases. Ferrite is a body-centred cubic form of iron, and its mechanical properties are relatively low in a pure state. However, the mechanical properties of ferrite can be improved with alloying, silicon ( $\mathrm{Si}$ ) being the most used 
strengthening element. When silicon alloying exceeds $3.2 \mathrm{wt} \%$, the alloys are defined as solid solution-strengthened ferritic ductile (or spheroidal) cast irons. ${ }^{8}$ These grades have also been added to the newest ductile iron standards, such as EN 1563:2011. High silicon (5 wt\%) additions can increase the ultimate tensile strength of a ferritic ductile iron to around $650 \mathrm{MPa}$, compared to $400 \mathrm{MPa}$ in ductile iron with $2.3 \mathrm{wt} \%$ silicon content. ${ }^{9}$ In addition, silicon strongly affects thermal conductivity. With a very low $(1.5 \mathrm{wt} \%) \mathrm{Si}$ content, the thermal conductivity of fully ferritic ductile iron is high, around $58 \mathrm{~W} / \mathrm{mK}$ at $200{ }^{\circ} \mathrm{C}$, while it is only $29 \mathrm{~W} /$ $\mathrm{mK}$ with a $4.3 \mathrm{wt} \%$ Si content. ${ }^{5}$

Additions of other alloying elements also contribute to a decrease in thermal conductivity. One of these is molybdenum (Mo), which is used in addition to silicon alloying in the production of SiMo-ductile cast irons. They are commonly used at elevated temperatures, up to $750{ }^{\circ} \mathrm{C}$, in components like exhaust manifolds. ${ }^{10}$ The thermal conductivities of SiMo cast irons are significantly lower (20 to $22 \mathrm{~W} / \mathrm{mK})^{11}$ than those of ductile iron alloys with only silicon as the main alloying element.

When cast irons cool below the A1-transformation temperature $\left(723{ }^{\circ} \mathrm{C}\right)$, excess carbon from austenite diffuses either to pearlite or graphite particles. Pearlite is a layered dual-phase material consisting of a ferrite matrix with iron carbide (cementite, $\mathrm{Fe}_{3} \mathrm{C}$ ) lamellae. The formation of pearlite is dependent on the carbon diffusion rate, and, with suitable alloying (copper and tin), this diffusion process can be slowed to create a partially or fully pearlitic matrix. Increasing the pearlite fraction of the matrix improves specific mechanical properties; for example, ultimate tensile strength increases, while ductility decreases. ${ }^{12}$ An increase in the pearlite fraction has an inverse effect on thermal conductivity. When the pearlite fraction increases from 0 to $100 \%$, thermal conductivity decreases from 39 to $30 \mathrm{~W} / \mathrm{mK}$ (Si content 2.3\%).

Thermal fatigue is an extremely complex failure mechanism, and cyclic loading and low material thickness further complicing this problem in cylinder heads. Consequently, many studies have been conducted on diesel-engine cylinder heads. ${ }^{13-15}$ Such studies have demonstrated some of the essential basic properties of materials under thermal loading. These are high thermal conductivity, a low coefficient of thermal expansion, a low modulus of elasticity, high strength properties and high creep resistance. Some studies show that molybdenum alloying increases the thermal fatigue resistance of cast irons, ${ }^{16}$ but such studies do not necessarily consider thermal conductivity and thermal expansion. With similar loading conditions, lower thermal conductivity leads to higher temperatures and therefore higher stresses. ${ }^{17}$ As some of these material properties are mutually incompatible, material selection is always a compromise.
Modelling the effect of Si content and pearlite fraction on mechanical and thermal properties is based on the general assumption that when material strength increases, thermal conductivity decreases. The effect of silicon content and the pearlite fraction on thermal conductivity has been studied in earlier work. ${ }^{5}$

Thermal conductivity of ferritic-pearlitic ductile irons can be estimated with the following equation: ${ }^{6}$

$$
\begin{aligned}
\lambda\left(\frac{\mathrm{W}}{\mathrm{mK}}\right)= & 72.56+0.06721 t-21.67 \mathrm{Si}(\%) \\
& -0.2458 \mathrm{Pe}(\%)-0.000161 t^{2}+2.173 \mathrm{Si}(\%)^{2} \\
& +0.00414 t \mathrm{Si}(\%)+0.0541 \mathrm{Si}(\%) \mathrm{Pe}(\%),
\end{aligned}
$$

Eqn. 1

where $\lambda$ is thermal conductivity, $t$ is temperature $\left({ }^{\circ} \mathrm{C}\right)$, $\mathrm{Si}(\%)$ is silicon content $\mathrm{wt} \%$ and $\mathrm{Pe}(\%)$ is the pearlite fraction.

Mechanical properties can be estimated with the following equations: ${ }^{6}$

$$
\begin{aligned}
\operatorname{UTS}(\mathrm{MPa})= & 0.0019 \mathrm{Pe}(\%)^{3}-0.200 \mathrm{Pe}(\%)^{2} \\
& +7.09 \mathrm{Pe}(\%)-3.28 \mathrm{Si}(\%)^{3}+39.5 \mathrm{Si}(\%)^{2} \\
& -45.6 \mathrm{Si}(\%)-1.87 E^{-5} t^{3}+0.0108 t^{2} \\
& -1.90 t+379
\end{aligned}
$$

Eqn. 2

$$
\begin{aligned}
\mathrm{YS}(\mathrm{MPa})= & 0.0011 \mathrm{Pe}(\%)^{3}-0.108 \mathrm{Pe}(\%)^{2}+2.88 \mathrm{Pe}(\%) \\
& -6.36 \mathrm{Si}(\%)^{3}+76.63 \mathrm{Si}(\%)^{2}-167.5 \mathrm{Si}(\%) \\
& -2.62 E^{-6} t^{3}+0.00923 t^{2}-1.729 t+357
\end{aligned}
$$

Eqn. 3

where UTS is tensile strength, $t$ is temperature $\left({ }^{\circ} \mathrm{C}\right), \mathrm{Si}(\%)$ is silicon content $\mathrm{wt} \%, \mathrm{Pe}(\%)$ is the pearlite fraction and YS is yield strength.

The effects of the pearlite fraction, silicon content and temperature on the elastic modulus are modelled in a similar way using earlier work. ${ }^{6}$

The effect of the pearlite fraction on the elastic modulus over the temperature regime (room temperature- $450{ }^{\circ} \mathrm{C}$ ) can be expressed as:

$$
\begin{aligned}
E_{\mathrm{Pe}}(\mathrm{Gpa})= & 4.27 * 10^{-6} \mathrm{Pe}(\%)^{3}+5.33 * 10^{-5} \mathrm{Pe}(\%)^{2} \\
& -0.020 \mathrm{Pe}(\%)-8.25 * 10^{-7} t^{3}+6.25 \\
& * 10^{-4} t^{2}-0.193 t+168 .
\end{aligned}
$$

Eqn. 4

The effect of silicon content over the temperature regime $\left(\mathrm{rt}-450{ }^{\circ} \mathrm{C}\right)$ can be expressed as:

$$
\begin{aligned}
E_{\mathrm{Si}}(\mathrm{Gpa})= & 4.43 \mathrm{Si}(\%)^{3}-41.0 \mathrm{Si}(\%)^{2}+122 \mathrm{Si}-1.15 \\
& * 10^{-6} t^{3}+7.611 * 10^{-4} t^{2}-1.90 t+50.0
\end{aligned}
$$

Eqn. 5 
The modulus of elasticity is then calculated:

$E(\mathrm{GPa})=\frac{\mathrm{Pe}(\%)}{100} E_{\mathrm{Pe}}+\frac{100-\mathrm{Pe}(\%)}{100} E_{\mathrm{Si}}$

Eqn. 6

\section{CFD and FE Analysis}

The thermal loads were based on computational fluid dynamics (CFD) analysis of the cylinder with STAR-CCM+ software. The thermal load wall data obtained from the combustion process were exported to a conjugate heat transfer model of the engine. Three cycles were simulated with updated surface temperatures from the conjugate heat transfer model. Stabilized temperature fields were then mapped to the FE mesh. The FE analysis was performed with Abaqus.

An elastic material model was used in the finite element calculations, the contacts being nonlinear with friction. The plasticity correction for fatigue life was performed with Ramberg-Osgood postprocessing. ${ }^{18}$

$\varepsilon=\frac{\sigma}{E}+\left(\frac{\sigma}{K}\right)^{\frac{1}{n}}$,

Eqn. 7

where $\varepsilon$ is true strain, $\sigma$ is true stress, $\mathrm{n}$ is the hardening exponent and $K$ is the strength coefficient.

The $\mathrm{k}$ and $\mathrm{n}$ factors of the Ramberg-Osgood model were calculated based on fatigue tests of ductile irons with $2.3 \%$ $\mathrm{Si}$ with different pearlite fractions from room temperature to $450{ }^{\circ} \mathrm{C}$. These values of these factors depend on the material's ultimate tensile strength and temperature.

$$
\begin{aligned}
K(\mathrm{Mpa})= & -2.57 * 10^{-6} \mathrm{UTS}^{3}+0.0034 * \mathrm{UTS}^{2}+0.225 \\
& * \mathrm{UTS}+1.25 * 10^{-5} \mathrm{YS}^{3}-0.021 \mathrm{YS}^{2} \\
& +9.86 \mathrm{YS}-1036
\end{aligned}
$$

Eqn. 8

$$
\begin{aligned}
n= & -3.23 * 10^{-11} U_{T S}^{3}+2.68 * 10^{-8} * \text { UTS }-8.24 \\
& * 10^{-5}+1.77 * 10^{-10} * K^{2}-5.64 * 10^{-7}-7.46 \\
& * 10^{-4} K-0.150
\end{aligned}
$$

Eqn. 9

The fatigue limit $F_{\mathrm{lm}}$ was defined on a similar basis:

$$
\begin{aligned}
F_{\operatorname{lm}}(\mathrm{MPa})= & 4.24 * 10^{-7} \mathrm{UTS}^{3}-7.77 * 10^{-4} \mathrm{UTS}^{2} \\
& +0.527 \mathrm{UTS}+2.76 * 10^{-6} t^{3}-0.016 t^{2} \\
& -0.02 t+145
\end{aligned}
$$

$N_{\mathrm{f}}=10^{5}\left(\frac{F_{\mathrm{lm}}}{\sigma_{\mathrm{a}}}\right)^{k}$

where $F_{1 \mathrm{~m}}$ is the fatigue limit; $\sigma_{\mathrm{a}}$ is stress amplitude; $k$ is the slope coefficient, which is calculated using

$N_{\mathrm{f}}(\mathrm{UTS})=1$

Eqn. 12
$1=10^{5}\left(\frac{F_{l m}}{\sigma_{i}}\right)^{k}$

Eqn. 13

$k=\frac{-\log \left(10^{5}\right)}{\log \left(\frac{F_{l m}}{\text { UTS }}\right)}$

Eqn. 14

The fatigue calculation was performed using the spectral load with one thermal cycle (heating up), and mechanical loads from gas exchange cycles for $12 \mathrm{~h}$. The spectral load was calculated with the Palmgren-Miner rule, ${ }^{19}$ which states that an individual stress cycle, which is part of a variable amplitude load history, will contribute the same fatigue damage as the same cycle when it is part of a constant amplitude load history:

$D_{\mathrm{PM}}=\sum \frac{n_{i}}{N_{f, i}}$,

Eqn. 15

where $D=1.0$ at failure; $n_{i}$, number of cycles, with stress $\Delta \sigma_{i} ; N_{\mathrm{f}, i}$, the number of constant amplitude cycles before failure. $^{19}$

The spectrum load is repeated until failure. The numbers of repetitions then correspond to expected lifetime in days. The maximum value of the calculation is 5.66 , which means 457000 cycles (days or 1270 years). In the results, it is defined as infinite lifetime.

\section{Analysis of Results}

The models presented in the earlier sections were used to analyse a cylinder head component in the three critical areas shown in Figure 1. The approach provides an indication of the most suitable material composition for further analysis. The composition boundaries selected for optimization were ferritic-pearlitic grades with silicon content from 1.5 to $2.5 \mathrm{wt} \%$ and a pearlite fraction from 0 to $100 \%$. In addition, two solution-strengthened fully ferritic grades, GJS-500-14 (Si 3.8\%) and GJS-600-10 (Si 4.3\%), were studied for comparison.

Thermal conductivity was calculated with the selected silicon content and pearlite fraction using Eqn. (1). Based on those, thermal balance and local temperatures were calculated. Maximum temperatures remained under $400{ }^{\circ} \mathrm{C}$ in the cylinder head, thus staying inside the applicable boundaries of the models used. Local mechanical properties were calculated based on silicon content, the pearlite fraction and temperature. These were used for fatigue calculation and lifetime estimation.

The component was divided into subareas with different loading conditions: the flame plate, which is subject to high mechanical loads and temperatures from combustion; the coolant channel area, which is also subject to high 


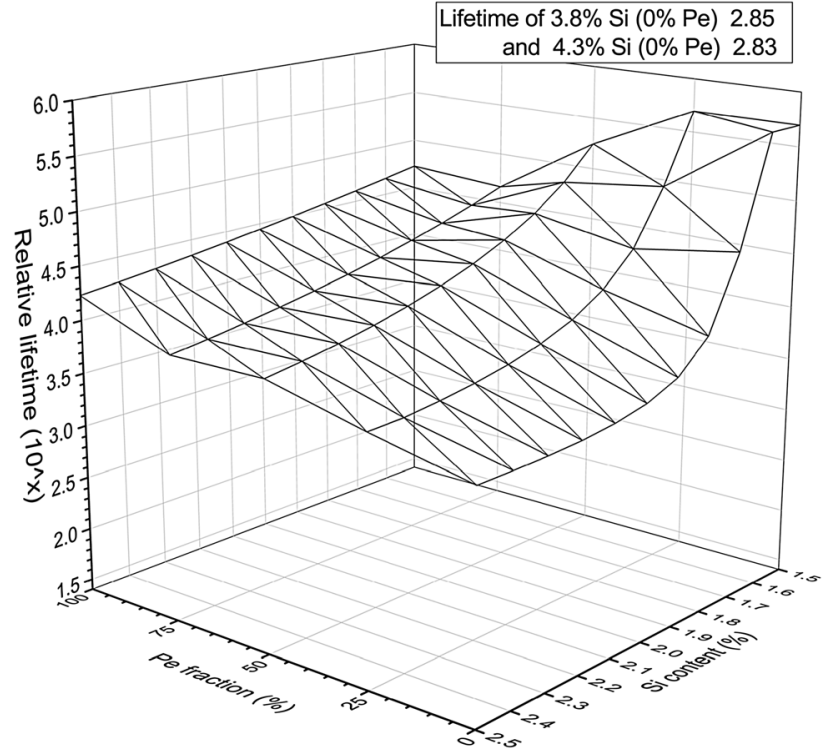

Figure 3. Lifetime prediction of flame plate area as a function of Si content (wt\%) and pearlite fraction.

mechanical loads and high temperature gradients; and the exhaust channel area, which experiences a high thermal load. The result of the calculations is expressed as the expected lifetime. Lifetime is an exponential factor of 10; for example, a value of 3 thus means 1000 load cycles. The calculation matrix was 11 ( $\mathrm{Si}$ content from 1.5 to 2.5 , step 0.1 ) by 5 (pearlite fraction from 0 to $100 \%$, step 25), resulting in 55 step combinations. Two separate combinations represent the solution-strengthened fully ferritic grades EN- GJS-500-14 (3.8\%) and EN-GJS-600-10 (4.3\% $\mathrm{Si})$. The results of all the calculations are displayed in Figures 3, 4 and 5.

The relative lifetime of the flame plate area, shown in Figure 3, with ferritic-pearlitic grades varied from infinite to 4.23. By contrast, the relative lifetime of GJS-500-14 was 3.08, and for GJS-600-10 it was 2.56. Grades with low silicon content and a low pearlite fraction had the most extended lifetimes. In turn, the relative lifetime of the exhaust port area, shown in Figure 4, varied from infinite to 3.2 with ferritic-pearlitic grades. The solutionstrengthened grades GJS-500-14 and GJS-600-10 had lifetimes of 2.85 and 2.83 , respectively. Similar to the flame plate area, in this calculation volume, the highest lifetime values were obtained with low silicon, low pearlite variants. In the coolant channel area, results shown in Figure 5, only one material, with $1.5 \mathrm{wt} \% \mathrm{Si}$ and $0 \%$ pearlite, achieved an infinite lifetime. The relative lifetimes of other ferritic-pearlitic variants were between 4.2 and 1.93; GJS-500-14 achieved a lifetime of 3.07 and GJS-60010 2.75. In this analysed volume, the lowest lifetime (1.93) was for a composition with $1.9 \mathrm{wt} \% \mathrm{Si}$ without any pearlite.

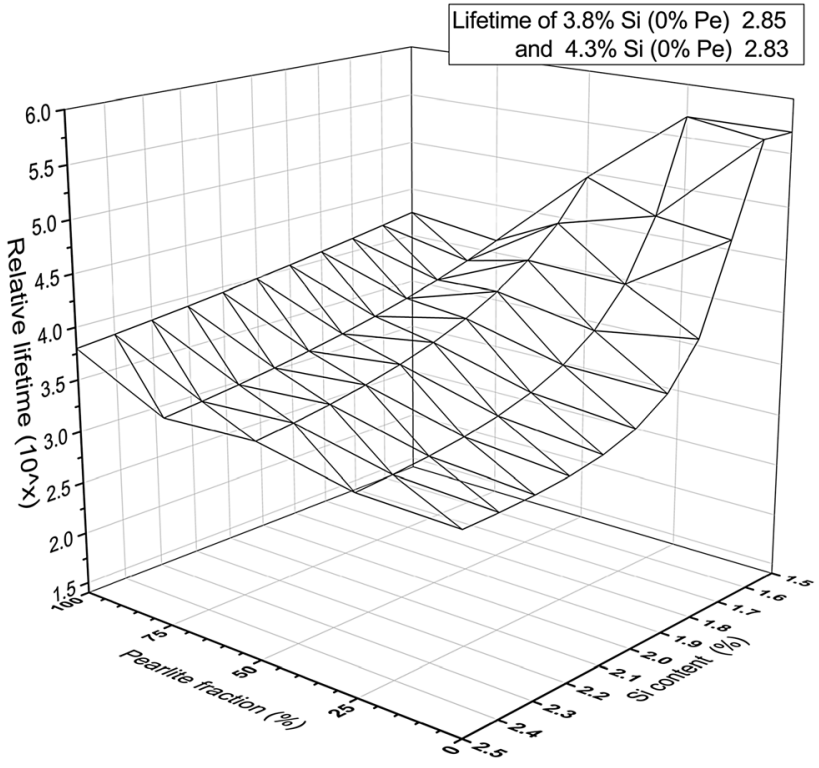

Figure 4. Lifetime prediction of exhaust port $\left(10^{X}\right.$ load cycles) as a function of Si content (wt\%) and pearlite fraction.

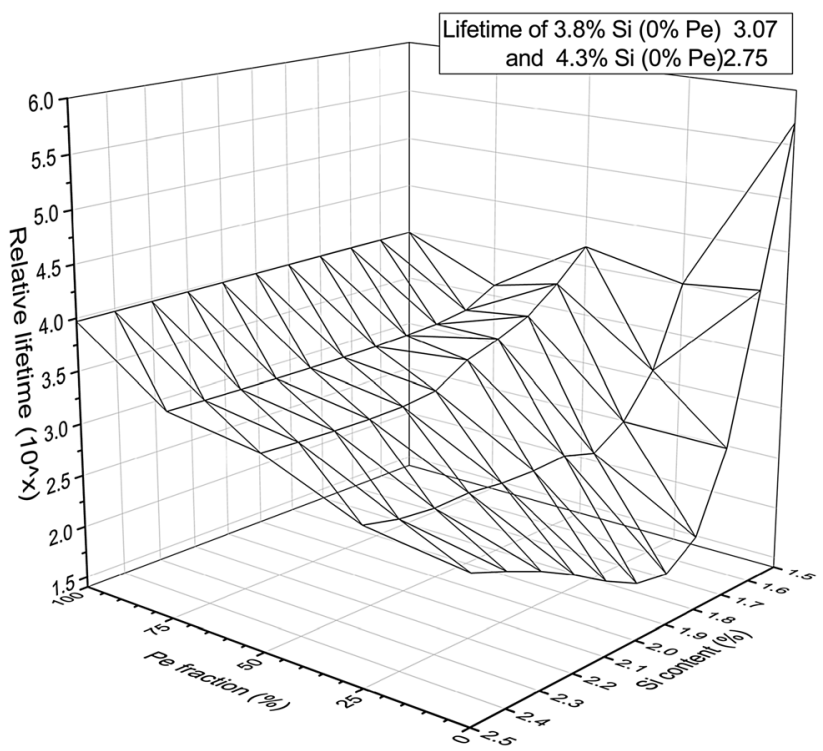

Figure 5. Lifetime prediction of coolant channels $\left(10^{x}\right.$ load cycles) as a function of Si content (wt\%) and pearlite fraction.

In a cylinder head, thermal and mechanical loads vary, and the variable temperature fields not only determine critical locations but are also decisive in limiting lifetime, as shown in the results of the analysis. The lifetime results in Figures 3 and 4 are slanted towards low Si content and a low pearlite fraction, favouring the maximization of thermal conductivity. When the decrease in conductivity reaches a certain threshold, a low pearlite fraction and a silicon content higher than $1.8 \%$, an increase in strength (increase in the pearlite fraction) begins to compensate for the loss of conductivity. In other words, higher silicon 
contents require higher pearlite fractions and, therefore, higher strength to offset the reduction in thermal conductivity. For comparison, only in fully pearlitic form does a composition of $2.5 \mathrm{wt} \% \mathrm{Si}$ achieve the same relative lifetime as a composition of $1.8 \mathrm{wt} \% \mathrm{Si}$ in a fully ferritic state. Coolant channel area loads are different from the other calculation volumes, and the relative lifetime field varies much more than in the other cases, as illustrated in Figure 5. The lowest lifetime prediction is for a case where silicon content is $1.9 \mathrm{wt} \%$, and the structure is fully ferritic. If either the silicon content or the pearlite fraction changes, lifetime increases.

\section{Discussion}

Factors such as lifetime are primary targets for the structural analysis of components. The composition of the materials in the simulations performed in this study covers a large portion of the ductile iron production window. That includes compositions equivalent to all general ductile iron grades from GJS-350 to GJS-700. The results of this study indicate that thermal conductivity plays a significant role in thermo-mechanically loaded component lifetimes. In the areas studied for the example component, compositions with the highest thermal conductivities, a fully ferritic matrix with low silicon content, achieved the highest lifetime estimates. For fully ferritic grades ( $0 \%$ pearlite) in hot surface areas (the exhaust port and flame plate), the results demonstrate that lower silicon content, and therefore higher thermal conductivity, results in longer lifetimes. On cooled surfaces (coolant channels), the results show a local minimum at $1.9 \mathrm{wt} \% \mathrm{Si}$ and a local maximum at $3.8 \mathrm{wt} \%$ (GJS-500-14). It should be noted that only two lifetime estimates were calculated at silicon levels over $2.5 \mathrm{wt} \% \mathrm{Si}$ (3.8 wt $\%$ and $4.3 \mathrm{wt} \%$ ).

By contrast, when the pearlite fraction rises, the lifetime prediction generally increases. Thus, in areas with lower temperature gradients, the impact of thermal conductivity on expected lifetime is lesser. However, a local minimum exists in the results at a composition of $75 \%$ pearlite in all studied areas. As a combination, higher silicon contents require higher pearlite fractions and, therefore, higher strength to compensate for the loss of thermal conductivity.

These simulations demonstrate that, at least in load cases like the one presented in this study, it is essential to select the correct iron composition. However, the local material property variation of casting and aspects such as the effect of wall thickness was not considered in this study. Thus, the approach described here is most useful for the preliminary selection of iron grade. A comprehensive analysis should consider the effects of production techniques and local microstructures through casting simulation. Final fatigue calculations should include the local pearlite fraction variation results from such other tools.
Taken together, the results of this study demonstrate the complexity of selecting the most suitable iron grade in thermally and mechanically loaded cases. Increasing strength by alloying ferrite or increasing the pearlite fraction is not a blanket solution due to the harmful effects of these strategies on thermal conductivity.

\section{Conclusions}

In this study, an approach for ductile iron property selection in thermo-mechanically loaded applications was developed and tested on a cylinder head. The following conclusions were made:

Thermal conductivity contributes significantly to component lifetime. Even if mechanical strengths are low, thermal conductivity compensates for this lack of strength. Nevertheless, for certain load cases, strength is favoured. For example, with higher silicon contents, an increase in the pearlite fraction extends lifetime, and, therefore, higher strength compensates for the loss of thermal conductivity. Thus, depending on the particular load combination, the most suitable material selection may vary considerably. As a consequence, thermal and mechanical loads should always be considered during design and material selection processes.

\section{Open Access}

This article is licensed under a Creative Commons Attribution 4.0 International License, which permits use, sharing, adaptation, distribution and reproduction in any medium or format, as long as you give appropriate credit to the original author(s) and the source, provide a link to the Creative Commons licence, and indicate if changes were made. The images or other third party material in this article are included in the article's Creative Commons licence, unless indicated otherwise in a credit line to the material. If material is not included in the article's Creative Commons licence and your intended use is not permitted by statutory regulation or exceeds the permitted use, you will need to obtain permission directly from the copyright holder. To view a copy of this licence, visit http://creativecommons.org/ licenses $/$ by $/ 4.0 /$.

\section{Funding}

Open access funding provided by Aalto University.

\section{REFERENCES}

1. Y. Hsu, A review of structural shape optimization. Comput. Ind. 25(1), 3-13 (1994). https://doi.org/10. 1016/0166-3615(94)90028-0 
2. R.T. Marler, Survey of multi-objective optimization methods for engineering. Struct. Multidiscipl. Optim. 26(6), 369-395 (2004). https://doi.org/10.1007/ s00158-003-0368-6

3. Y. Carson, Simulation optimization: methods and applications, in Winter Simulation Conference Proceedings (1997), pp. 118-126

4. K. Mollenhauer, K. Mollenhauer, H. Tschoke, Handbook of Diesel Engines (Springer, Berlin, 2010), pp. 195-219

5. K. Jalava, Effect of silicon and microstructure on spheroidal graphite cast iron thermal conductivity at elevated temperatures. Int. J. Metalcast. 12(3), 480-486 (2018). https://doi.org/10.1007/s40962-0170184-1

6. J. Laine, K. Jalava, J. Vaara, K. Soivio, T. Frondelius, J. Orkas, The mechanical properties of ductile iron at intermediate temperatures: the effect of silicon content and pearlite fraction. Int. J. Metalcast. (2020). https:// doi.org/10.1007/s40962-020-00473-8

7. J.R. Davis, J.R. Davis, Metals handbook. Desk ed., 2nd edn. Materials Park, Oh.: ASM International; 1998:1(electronic edition 2000), pp. 314-320

8. R. Larker, Solution strengthened ferritic ductile iron ISO 1083/JS/500- 10 provides superior consistent properties in hydraulic rotators - solution strengthened ferritic ductile iron ISO 1083/JS/500- 10 provides superior consistent properties in hydraulic rotators. China Found. 6(4), 343-351 (2009)

9. A. Alhussein, Influence of silicon and addition elements on the mechanical behavior of ferritic ductile cast iron. Mater. Sci. Eng. A 605, 222-228 (2014). https://doi.org/10.1016/j.msea.2014.03.057

10. S. Biswas, Use of published experimental results to validate approaches to gray and ductile iron mechanical properties prediction. Int. J. Metalcast. 11(4), 656-674 (2017). https://doi.org/10.1007/s40962-0160126-3
11. M. Riebisch, Impact of carbide-promoting elements on the mechanical properties of solid-solutionstrengthened ductile iron. Int. J. Metalcast. (2019). https://doi.org/10.1007/s40962-019-00358-5

12. E. Autere, Y. Ingman, P. Tennilä, Valimotekniikka (Insinööritieto Oy, Helsinki, 1982), pp. 196-202

13. R.B. Gundlach, Wirkung von legierungselementen auf die eigenschaften von grauguss bei hoeheren temperaturen. Giessereipraxis 1-2, 1-25 (1985)

14. K. Roehrig, Thermal fatigue of gray and ductile irons, in 82nd Annual Meeting; Detroit; Mich.; 24-28 April 1978 (1978), pp. 75-88

15. J. Campbell, Thermal fatigue in diesel engine cylinder head castings. Conference Proceeding. (1998)

16. Y. Park, Effects of molybdenum on thermal fatigue resistance of ductile and compacted graphite irons (retroactive coverage). Trans. Am. Foundrymen's Soc. 95, 267-272 (1987)

17. F. Szmytka, Thermo-mechanical fatigue resistance characterization and materials ranking from heat-fluxcontrolled tests. Application to cast-irons for automotive exhaust part. Int. J. Fatigue 55, 136-146 (2013)

18. W. Ramberg, W.R. Osgood, Description of stressstrain curves by three parameters (National Advisory Committee for Aeronautics, Washington DC, 1943)

19. K.A. Macdonald, Fracture and fatigue of welded joints and structures. (Woodhead Publishing, 2011), pp. 214-22. Retrieved from https://app.knovel.com/ hotlink/pdf/id:kt008WUF01/fracture-fatigue-welded/ assessment-based-s-n

Publisher's Note Springer Nature remains neutral with regard to jurisdictional claims in published maps and institutional affiliations. 